\title{
Rumen degradation of the rind part of normal and brown- midrib maizes grown at high and low temperature
}

\author{
A Cornu, E Grenet, JM Besle, MP Maillot, M Taché, M Jamot, M Fabre
}

INRA, Unité Digestion Microbienne, Theix, 63122 St-Genès Champanelle, France

\begin{abstract}
Plant anatomy and their cell wall properties may vary according to the growth temperature (Wilson et al, 1991, Netherlands J Agric Sc, 39, 31-48).

Normal (N) and bm3 (bm) maize lines were grown in a culture chamber of either $25^{\circ} \mathrm{C}$ ("N25", "bm25") or $18^{\circ} \mathrm{C}$ ("N18", "bm18"). Stalks were harvested at the silking stage of the plants and the pith was removed. Cell wall residues (CW) were prepared and fractionated according to Jarrige (1961, Ann Biol Anim Bioch Biophys, 1, 163-212). CW were also analysed for lignin (acetyl bromide method of Morrison, 1972, J Sci Fd Agric, 23, 455-463), for polysaccharide (alditol acetate method of Blakeney et al, 1983, Carbohyd Res, 113, 291299), and for saponifiable phenolic acids (Scalbert et al, 1985, Phytochemistry, 24, 1359-1362). Rumen degradability was studied using the nylon bag method (Demarquilly and Chenost, 1969, Ann Zootechn, 18, 419-436). Microscopic observations were performed on frozen stalk samples from the internode bearing the female ear.

Scanning electron microscopy allowed to visualise thicker sclerenchyma and fiber cell walls in plants cultivated at $25^{\circ} \mathrm{C}$. When observed with light microscope, bm25 sample exhibited Maüle and phloroglucinol positive parenchyma cell walls, indicating the presence of "lignin-like" compounds in this usually unlignified tissue. Cell wall contents were not different. As expected, bm cell walls had lower lignin contents than normal ones although the
\end{abstract}

overall values were low, and lower $p$-coumaric acid ( $p C A$ ) contents.

Cell wall recovery as polysaccharide and lignin was lower in N18 than in other plants. This result, repeatedly obtained and confirmed by using two different methods, is due to a lower yield of hydrolysis of N18 cell walls during polysaccharide analysis. On the whole, the growth temperature had no drastic effect on cell wall composition, but cell walls from the plants grown at $18^{\circ} \mathrm{C}$ contained more arabinose and saponifiable ferulic acid (FA) and less cellulose (glucose) and saponifiable $p$-coumaric acid ( $p C A)$.

The dry matter disappearance (DMdis) after 48 $\mathrm{h}$ rumen incubation were much higher in bm samples $(+16 \%)$, and not affected by the growth temperature, as neither was the cell wall disappearance (CWdis) in this line. In the normal line however, while the decrease in growth temperature seemed not to affect the DMdis, it enhanced clearly the CWdis $(+7 \%)$.

After $6 \mathrm{~h}$ rumen incubation, the effect of the growth temperature on CWdis was exactly the same as the effect of the bm3 mutation $(+7 \%)$. Scanning electron microscopy of $6 \mathrm{~h}$-incubated samples showed that the parenchyma in N18 had entierly disappeared whereas in the other samples it was still present.

It is concluded that the growth temperature may modify cell wall properties, resulting in different susceptibility to rumen microorganisms.

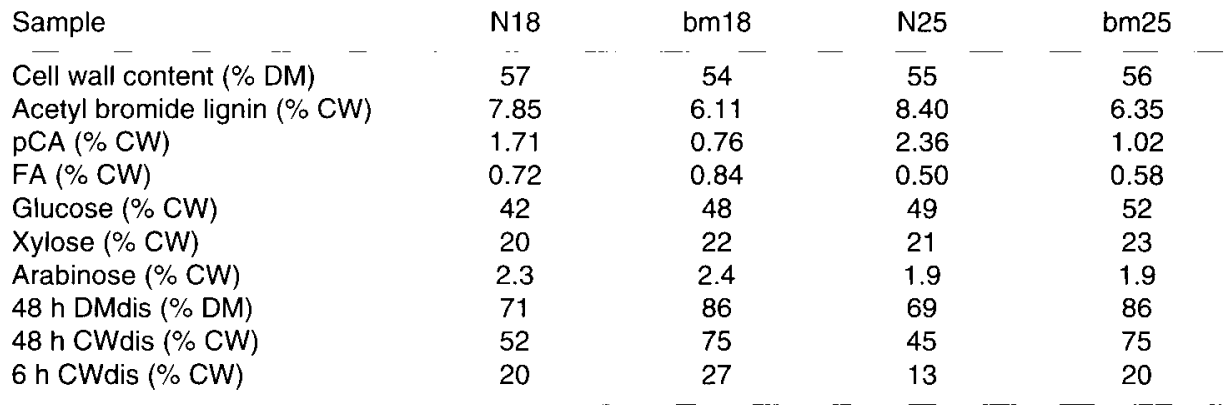

